\title{
High flexion total knee arthroplasty using short posterior flange of femoral
}

\section{component mid-term results}

\author{
Sang Jin Lee
}

Department of Orthopedic Surgery, Haeundae Paik Hospital, College of Medicine, Inje University,

Busan, Korea

\section{RESEARCH}

Please cite this paper as: Lee SJ. High flexion total knee arthroplasty using short posterior flange of femoral component mid-term results. AMJ 2019;12(1):27-33.

https://doi.org/10.21767/AMJ.2018.3549

\section{Corresponding Author:}

\section{Sang Jin Lee}

Department of Orthopedic Surgery, Haeundae Paik Hospital, College of Medicine, Inje University, Busan, Korea

Email: sjinnie@paik.ac.kr

\section{ABSTRACT}

\section{Background}

High-flexion designs for total knee arthroplasty were introduced and promoted greater and safer knee flexion. However, early loosening of the femoral component related to the deep flexion was reported with high incidence.

\section{Aims \\ Contrary to conventional high-flexion designs, another femoral component was designed to allow high flexion by shortening the length of posterior condylar flange of femoral component. Authors evaluated the outcomes of high flexion total knee arthroplasty using short posterior flange of femoral component at least 3 years after the operation and to assess the occurrence of periprosthetic osteolysis and loosening.}

\section{Methods}

Of the patients who underwent total knee arthroplasty using short posterior flange of femoral component between August 2011 and November 2014, 65 patients (94 knees) were enrolled. Knee Society Knee score, Knee Society Function score, maximal flexion angle were evaluated. Relationship between postoperative maximal flexion and radiographic factors including posterior tibial slope and femoral condylar offset was analyzed. Also, the occurrence of periprosthetic osteolysis and loosening was assessed.

Results

The maximal flexion was improved at the final follow-up $(P<0.05)$. The knee score and function score were also improved after operation $(P<0.05)$. The postoperative posterior tibial slope and femoral condylar offset showed no significant relationship with the postoperative maximal flexion angle. The periprosthetic osteolysis occurred in 3 cases but loosening did not occur at the final follow-up.

\section{Conclusion}

High flexion total knee arthroplasty using short posterior flange of femoral component is considered as a good alternative to conventional high-flexion prosthesis.

\section{Key Words}

Total knee arthroplasty, high-flexion, loosening

\section{What this study adds:}

\section{What is known about this subject?}

Total knee replacement arthroplasty using conventional high-flexion prosthesis showed better range of motion. However, early loosening of the femoral component was reported with high incidence.

\section{What new information is offered in this study?}

Total knee arthroplasty using femoral component which has shorter posterior flange than conventional high-flexion prosthesis showed satisfactory results and no early periprosthetic loosening.

3. What are the implications for research, policy, or practice?

High flexion total knee arthroplasty using short posterior flange of femoral component is considered as a good alternative to conventional high-flexion prosthesis. 


\section{Background}

Patient satisfaction after total knee replacement arthroplasty (TKA) depends on range of motion (ROM) and maximal flexion as well as on improvement of pain. ${ }^{1-3}$ Knee flexion is one of the most important factors in performing many daily routine activities. Climbing up and down the stairs requires $90^{\circ}-120^{\circ}$ of flexion, whereas kneeling, squatting and sitting cross-legged require beyond $140^{\circ}$ of flexion. ${ }^{4,5}$ Especially, more flexion of the knee joint is required in Asian population with their cultural and religious environments. $^{6}$

Under the influence of this requirement, several highflexion designs for TKA were introduced and promoted greater and safer flexion without increasing the risk of failure compared with standard designs. Thereafter highflexion prosthesis showed better ROM and more satisfaction in several studies. ${ }^{7-9}$ However, in several studies, early loosening of the femoral component related to the deep flexion provided by high-flexion TKA was reported with high incidence and concerns have been raised about early aseptic loosening in high-flexion design. ${ }^{10,11}$

Contrary to other high-flexion designs, Vega Knee System (B Braun-Aesculap, Tuttlingen, Germany) was designed to allow high flexion after TKA by shortening the length of posterior condylar flange of femoral component instead of removing an additional $2 \mathrm{~mm}$ of bone from the posterior femoral condyle. (Figure 1) In addition to the shorter posterior condylar flange of femoral component, the cam and post mechanism was thickened and elongated in order to provide greater jump distance in deep degrees of flexion while providing proper roll back and to prevent posterior subluxation of tibia.

The purpose of this study was to evaluate the clinical and radiographic outcomes of TKA using short posterior flange of femoral component and the occurrence of periprosthetic osteolysis and loosening after operation. Also, the relationship between postoperative maximal flexion and radiographic factors including posterior tibial slope and femoral condylar offset was assessed.

\section{Method}

\section{Materials}

Of the patients who underwent TKA using Vega Knee System performed by the same surgeon at our institution between August 2011 and November 2014, 65 patients (94 knees) with a minimum follow-up of 38 months were enrolled in this retrospective study. Six cases of the rheumatoid arthritis were excluded. Bilateral TKA was performed in 58 knees (29 patients) and unilateral TKA was performed in 36 knees. There were 53 females ( 77 knees) and 12 males (17 knees). The diagnosis was osteoarthritis and the Kellgren-Lawrence grade was 3 or 4 in all of the 94 knees. The mean age of the patients at the time of surgery was $73.4 \pm 7.2$ years' ranging from 55 to 83 years and the mean follow-up period was $47.3 \pm 2.9$ months ranging from 38 to 63 months.

\section{Operative technique}

Prior to the operation, full-length weight bearing radiographs were obtained showing the hip, knee, and ankle joints. The angles of the femoral and tibial cuts, and the desired position of the entry hole, were planned before surgery. All the operations were performed by the same surgeon using midline incision and medial parapatellar approach. A medial soft tissue release was done by elevating a periosteal sleeve from the anteromedial tibia to the posteromedial aspect according to the degree of preoperative deformity. After lateral subluxation of the patella, the femoral condyle was resected to remove a thickness of bone equal to that of the femoral component to be inserted. The valgus angle of femoral resection was made using an intramedullary guide. The anteroposterior cutting was performed using an anterior referencing system. The femoral component was placed in $3^{\circ}$ to $5^{\circ}$ of external rotation to the posterior condyles, and this was ascertained with the help of the transepicondylar line. Using an extramedullary tibial guide, $6 \mathrm{~mm} \sim 10 \mathrm{~mm}$ of tibial bone was resected to obtain a surface that was perpendicular to the shaft of the tibia in the coronal plane, with a $7^{\circ}$ posterior slope in the sagittal plane. The posterior cruciate ligament was resected in all knees. Stability and alignment were measured using the trial components, and the balancing of the soft tissues was assessed in both flexion and extension state. Additional resection was performed on overhanged portion of the posterior femoral condyle. All the components were cemented after irrigation, drying and pressurization of the cement. Patelloplasty rather than patellar resurfacing was performed in all knees. Patelloplasty consisted of electrocautery of the patellar rim to provide denervation, removal of osteophytes and reduction of size of the patella. All patients received prophylactic antibiotics and anticoagulation with lowmolecular weight heparin for one week. Quadriceps strengthening exercise and continuous passive movement were begun immediately after operation. Weight bearing was allowed from three days after operation. Going up and down the stairs were recommended from eight weeks after operation. In addition, the patients were advised not to take 
kneeling or squatting position after surgery even if they could kneel and squat easily for longevity of the prosthesis.

\section{Assessment and analysis}

The patients were reviewed before operation and at six weeks, three months, six months, one year, and annually thereafter.

Clinical parameters, including Knee Society Knee score (KS), Knee Society Function score (FS), maximal flexion, ROM, and complications, were evaluated. ${ }^{12}$ Pre-operative factors related with the postoperative ROM were also analyzed including age, gender, flexion contracture, deformity and preoperative ROM. Maximum flexion was measured prior to surgery and at every follow-up using a manual goniometer with the arms aligned along the long axes of the femur and tibia on the lateral side of the knee joint. Flexion contracture was measured and reported similarly. Range of movement was calculated by subtracting the flexion contracture from maximum flexion.

Radiographic parameters included both knee standing anteroposterior, lateral and Merchant's view. The width of the radiolucent line, osteolysis and loosening were measured on the basis of seven zones on the lateral radiograph of the femur, seven on an anteroposterior radiograph of the tibia, and three on a lateral radiograph of the tibia, as analyzed using the America Knee Society Radiographic Scoring System. ${ }^{13}$ The posterior tibial slope (PTS) was defined as the angle between a line perpendicular to the proximal tibial anterior cortex and a line parallel to the tibial medial plateau on the lateral view. The femoral condylar offset (FCO) was measured as the distance from the tangent of the femoral diaphysis posterior cortex to the apex of the posterior femoral condyle preoperatively and to the apex of the posterior femoral component postoperatively (Figure 2).

All clinical results were analyzed using paired $t$ test. Radiographic factors affecting postoperative ROM and maximal flexion were also analyzed using correlation analysis (Spearman rank test). Differences were considered statistically significant at $P<0.05$, and the calculations were performed using SPSS version 12 (SPSS Inc., Chicago, Illinois).

\section{Results}

The mean preoperative flexion contracture was $4.2^{\circ}$ (range $0-25^{\circ}$ ) which was reduced to $1.2^{\circ}$ (range $0-15^{\circ}$ ) at the final follow-up $(P<0.05)$. The mean preoperative ROM was $120.4 \pm 13.5^{\circ}$ (range $95-140^{\circ}$ ) which was increased to
$132.1 \pm 7.3^{\circ}$ (range $115-140^{\circ}$ ) at the final follow-up $(P<0.05)$. The mean preoperative maximal flexion was $125.3 \pm 9.3^{\circ}$ (range $100-140^{\circ}$ ) which was increased to $132.5 \pm 6.7^{\circ}$ (range $\left.115-140^{\circ}\right)$ at the final follow-up $(P<0.05)$. The mean preoperative KS and FS were $53.8 \pm 7.3$ and $46.5 \pm 7.6$. At the final follow-up, the mean KS and FS were improved to $89.3 \pm 5.2$ and $77.3 \pm 5.7(P<0.05)$ (Table 1$)$.

Pre-operative factors including age, gender, flexion contracture, deformity and preoperative ROM showed no significant relationship with the postoperative maximal flexion angle. The mean postoperative PTS was $7.3 \pm 2.8^{\circ}$ (range $2-16^{\circ}$ ) and the mean FCO was increased from $32.3 \pm 2.8 \mathrm{~mm}$ to $34.9 \pm 4.9 \mathrm{~mm}$ after operation. The postoperative PTS and FCO showed no significant relationship with the postoperative maximal flexion angle. (PTS; $\mathrm{R}=0.084, \mathrm{p}=0.420$ / $\mathrm{FCO} ; \mathrm{R}=0.014, \mathrm{p}=0.892$ ) (Figures 3 and 4).

There were three cases of periprosthetic osteolysis but no other complications including component loosening, instability and patella subluxation. Two-stage revision was performed in one knee because of deep infection with Methicillin-sensitive Staphylococcus aureus, and in two knees with Methicillin-resistant Staphylococcus aureus after surgery.

\section{Discussion}

Although TKA has been a satisfactory treatment of advanced osteoarthritis to achieve painless walking, restoring the preoperative high-flexion activities is one of the major problems that remain to be solved in Asian countries. $^{5,14}$

Recently, high-flexion TKA designs were developed to safely permit deep flexion of knee joint and to accommodate resumption of high-flexion daily activities. However, results of these high-flexion TKA designs have been variable. Several studies reported improved postoperative ROM (ranged from $122^{\circ}-138^{\circ}$ ) and satisfaction with daily activities, whereas others have found no major improvement. ${ }^{7,15-19}$ Furthermore, two clinical studies of high-flexion TKA have reported progressive radiolucent lines in 14 per cent to 48 per cent of the femoral component and high incidence of early aseptic loosening. ${ }^{10,11}$ According to these studies, the early aseptic loosening was caused by postoperative deep flexion ability. Cho et al. found early aseptic loosening at a mean period of 24 months and more progressive radiolucent lines in 67.7 per cent of patients with TKA who could squat than 20.2 per cent of patients who could not squat. ${ }^{10}$ To obtain more degrees of flexion, 
high flexion design requires $2 \mathrm{~mm}$ of additional bone resection from posterior condyles, which may weaken the bone supporting load from the femoral component and cause instability. Several studies reported the increased contact stress during deep flexion and greater wear and early loosening of the prosthesis. ${ }^{10,11,22}$ However, a number of clinical studies have suggested conflicting findings with only a few instances of loosening after high-flexion TKA. $^{8,17,20,21}$ Therefore, it is necessary to consider other factors that could have been responsible for the cases of aseptic loosening. Several previous studies have identified implant design, preparation of bone, cementing technique, implant positioning, and soft-tissue balancing as possible causes of femoral loosening. ${ }^{23-25}$ Also, a large random comparative study involving both conventional and highflexion prostheses is essential to conclude the cause of early aseptic loosening. The smaller femoral radius of curvature and more shortened posterior flange of the Vega ${ }^{\circ}$ Knee System decrease contact stress at deep flexion angle. In addition, it has a modified cam and post mechanism with increased jump distance to avoid dislocation at angle of high-flexion. In this study, the mean maximal flexion angle after TKA using Vega ${ }^{\circ}$ Knee System was more than $130^{\circ}$ and ranged from $115^{\circ}-140^{\circ}$. This result was not inferior to the results of conventional high-flexion designs which were from $131^{\circ}-138^{\circ}$ of the mean maximal flexion and ranged from $95^{\circ}-150^{\circ} .^{7-11}$ Also, there was no complication related with prosthesis including aseptic loosening. In consideration of the concerns about the high incidence of early aseptic loosening in conventional high-flexion designs, no additional bone cutting of posterior femoral condyle and less contact stress due to short posterior flange of femoral component could be another solution for the high-flexion TKA.

According to the past studies, two important factors that have been associated with the maximal flexion after TKA include posterior femoral condylar offset (FCO) and posterior tibial slope (PTS). Malviya et al. reported that $1^{\circ}$ of extra PTS increase the maximal flexion angle by an average of $2.3^{\circ}$ in 101 knees after posterior cruciate ligament (PCL)retaining TKA. ${ }^{26}$ Bellemans et al. also reported that that $1^{\circ}$ of additional PTS increase the maximal flexion by an average of $1.7^{\circ}$ after PCL-retaining TKA. ${ }^{27}$ On the other hand, the other studies showed that the correlation between PTS and maximal knee flexion that can be observed after PCLretaining TKA was not noted after PCL-sacrificing TKA. ${ }^{28-30}$ Arabori et al. reported that FCO was correlated with flexion angle in PCL-retaining knees but not in PCL-sacrificing knees after simultaneous PCL-retaining TKA on one side and PCLsacrificing TKA on the other side. ${ }^{31}$ Vega ${ }^{\circledR}$ Knee System has fixed insert as a substitute for the PCL. In this study, radiographic results corresponded with the past studies. Significant correlation was not observed between PTS and maximal flexion angle after PCL-sacrificing TKA using Vega Knee System. Also, no correlation was found between the postoperative maximal flexion angle and FCO.

The limitations of this study include lack of comparison group and retrospective study design. Therefore, this study results should be approved with further clinical and biomechanical studies with prospective design.

\section{Conclusion}

Total knee arthroplasty using femoral component which has shorter length of posterior flange than conventional highflexion prosthesis provided satisfactory maximal flexion at minimum 3 years follow-up. Also, the periprosthetic osteolysis and loosening which occurred at the early postoperative period from using conventional high-flexion prosthesis did not occur. Therefore, high flexion total knee arthroplasty using short posterior flange of femoral component is considered as a good alternative to conventional high-flexion prosthesis.

\section{References}

1. Anouchi YS, McShane M, Kelly F Jr, et al. Range of motion in total knee replacement. Clin Orthop. 1996;331:87-92.

2. Chew JTH, Stewart NJ, Hanssen AD, et al. Differences in patellar tracking and knee kinetics among three different total knee designs. Clin Orthop. 1997;345:87-98.

3. Dennis DA, Komistek RD, Stiehl JB, et al. Range of motion after total knee arthroplasty: the effect of implant design and weight-bearing conditions. J Arthroplasty. 1998;13(7):748-752. https://doi.org/10.1016/S08835403(98)90025-0

4. Rowe PJ, Myles CM, Walker C, et al. Knee joint kinematics in gait and other functional activities measured using flexible electrogoniometry: how much knee motion is sufficient for normal daily life? Gait Posture. 2000;12:143-155. https://doi.org/10.1016/S0966-6362(00)00060-6

5. Mulholland SJ, Wyss UP. Activities of daily living in nonWestern cultures: range of motion requirements for hip and knee joint implants. Int J Rehabil Res. 2001;24:191198.

6. Park KK, Chang CB, Kang YG, et al. Correlation of maximum flexion with clinical outcome after total knee replacement in Asian patients. J Bone Joint Surg Br. 2007;89:604-608.

https://doi.org/10.1302/0301-620X.89B5.18117

7. Huang HT, Su JY, Wang GJ. The early results of high-flex 
total knee arthroplasty: a minimum of 2 years of followup. J Arthroplasty. 2005;20:674-679.

https://doi.org/10.1016/j.arth.2004.09.053

8. Kim TH, Lee DH, Bin SI. The NexGen LPS-flex to the knee prosthesis at a minimum of three years. J Bone Joint Surg Br. 2008;90:1304-1310.

https://doi.org/10.1302/0301-620X.90B10.21050

9. Weeden $\mathrm{SH}$, Schmidt R. A randomized, prospective study of primary total knee components designed for increased flexion. J Arthroplasty. 2007;22:349-352. https://doi.org/10.1016/j.arth.2006.04.007

10. Cho SD, Youm YS, Park KB. Three- to six-year follow-up results after high-flexion total knee arthroplasty: can we allow passive deep knee bending? Knee Surg Sports Traumatol Arthrosc. 2011;19:899-903. https://doi.org/10.1007/s00167-010-1218-x

11. Han HS, Kang SB, Yoon KS. High incidence of loosening of the femoral component in Legacy posterior stabilisedflex total knee replacement. J Bone Joint Surg $\mathrm{Br}$. 2007;89:1457-1461. https://doi.org/10.1302/0301-620X.89B11.19840

12. Insall JN, Dorr LD, Scott RD, et al. Rationale of the Knee Society clinical rating system. Clin Orthop. 1989;248:1314.

13. Ewald FC. The Knee Society total knee arthroplasty roentgenographic evaluation and scoring system. Clin Orthop. 1989;248:9-12.

14. Kurosaka M, Yoshiya S, Mizuno $K$, et al. Maximizing flexion after total knee arthroplasty: the need and the pitfalls. J Arthroplasty. 2002;17:59-62. https://doi.org/10.1054/arth.2002.32688

15. McCalden RW, MacDonald SJ, Bourne RB, et al. A randomized controlled trial comparing 'high-flex' vs 'standard' posterior cruciate substituting polyethylene tibial inserts in total knee arthroplasty. J Arthroplasty. 2009;24:33-38.

https://doi.org/10.1016/j.arth.2009.03.013

16. Sharma A, Komistek RD, Scuderi GR, et al. High-flexion TKA designs: what are their in vivo contact mechanics? Clin Orthop Relat Res. 2007;464: 117-126. doi: 10.1097/BLO.0b013e318157e478

17. Kim YH, Sohn KS, Kim JS. Range of motion of standard and highflexion posterior stabilized total knee prostheses. A prospective, randomized study. J Bone Joint Surg Am. 2005;87:1470-1475. doi:10.2106/JBJS.D.02707

18. Mehin R, Burnett RS, Brasher PM. Does the new generation of high-flex knee prostheses improve the post-operative range of movement? A meta-analysis. J Bone Joint Surg Br. 2010;92:1429-1434. https://doi.org/10.1302/0301-620X.92B10.23199
19. Nutton RW, van der Linden $\mathrm{ML}$, Rowe PJ, et al. A prospective randomised double-blind study of functional outcome and range of flexion following total knee replacement with the NexGen standard and high flexion components. J Bone Joint Surg Br. 2008;90:37-42. https://doi.org/10.1302/0301-620X.90B1.19702

20. Kim YH, Choi Y, Kim JS. Comparison of a standard and a gender-specific posterior cruciate-substituting highflexion knee prosthesis: a prospective, randomized, short-term outcome study. J Bone Joint Surg Am. 2010;92:1911-1920. doi: 10.2106/JBJS.I.00910

21. Kim YH, Choi Y, Kwon OR, et al. Functional outcome and range of motion of high-flexion posterior cruciateretaining and high-flexion posterior cruciate-substituting total knee prostheses. A prospective, randomized study. J Bone Joint Surg Am. 2009;91:753-760. doi: 10.2106/JBJS.H.00805

22. Nagura T, Dyrby CO, Alexander EJ, et al. Mechanical loads at the knee joint during deep flexion. J Orthop Res. 2002;20(4):881-886. doi:10.1016/S07360266(01)00178-4

23. Cameron HU, Fedorkow DM. Review of a failed knee replacement and some observations on the design of a knee resurfacing prosthesis. Arch Orthop Trauma Surg. 1980;97:87-89.

24. Gioe TJ, Killeen KK, Grimm K, et al. Why are total knee replacements revised? analysis of early revision in a community knee implant reg istry. Clin Orthop. 2004;428:100-106.

doi: 10.1097/01.blo.0000147136.98303.9d

25. Lotke PA, Ecker ML. Influence of positioning of prosthesis in total knee replacement. J Bone Joint Surg Am. 1977;59-A:77-79.

26. Malviya A, Lingard EA, Weir DJ, et al. Predicting range of movement after knee replacement: the importance of posterior condylar offset and tibial slope. Knee Surg Sports Traumatol Arthrosc. 2009;17:491-498. doi: 10.1007/s00167-008-0712-x

27. Bellemans J, Robijns F, Duerinckx J, et al. The influence of tibial slope on maximal flexion after total knee arthroplasty. Knee Surg Sports Traumatol Arthrosc. 2005;13:193-196. doi 10.1007/s00167-004-0557-x

28. Bauer T, Biau D, Colmar M, et al. Influence of posterior condylar offset on knee flexion after cruciate-sacrificing mobile-bearing total knee replacement: a prospective analysis of 410 consecutive cases. Knee. 2010;17:375380.

doi: 10.1016/j.knee.2009.11.001

29. Kansara D, Markel DC. The effect of posterior tibial slope on range of motion after total knee arthroplasty. J 
Arthroplasty. 2006;21:809-813.

https://doi.org/10.1016/j.arth.2005.08.023

30. Piazza SJ, Delp SL, Stulberg SD, et al. Posterior tilting of the tibial component decreases femoral rollback in posterior-substituting knee replacement: a computer simulation study. J Orthop Res. 1998;16:264-270. https://doi.org/10.1002/jor.1100160214

31. Arabori M, Matsui N, Kuroda R, et al. Posterior condylar offset and flexion in posterior cruciate-retaining and posterior stabilized TKA. J Orthop Sci. 2008;13:46-50. doi: 10.1007/s00776-007-1191-5

\section{PEER REVIEW}

Not commissioned. Externally peer reviewed.

\section{CONFLICTS OF INTEREST}

The authors declare that they have no competing interests.

\section{FUNDING}

None

\section{ETHICS COMMITTEE APPROVAL}

This study was approved by our institutional review board. (No. 129792-2013-123)

Figure 1: Femoral component of the Vega Knee System. Compared with conventional high-flexion designs, length of the posterior condylar flange is shorter.

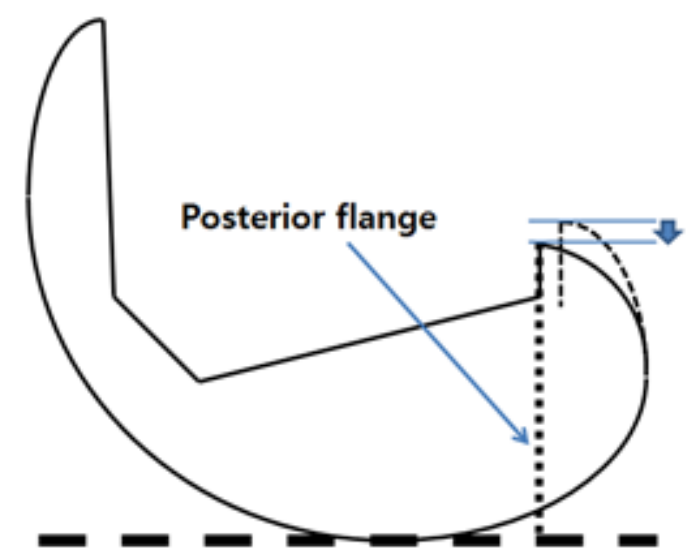

Figure 2: Measurement of posterior tibial slope and femoral condylar offset (a) before operation (b) after operation

(a)

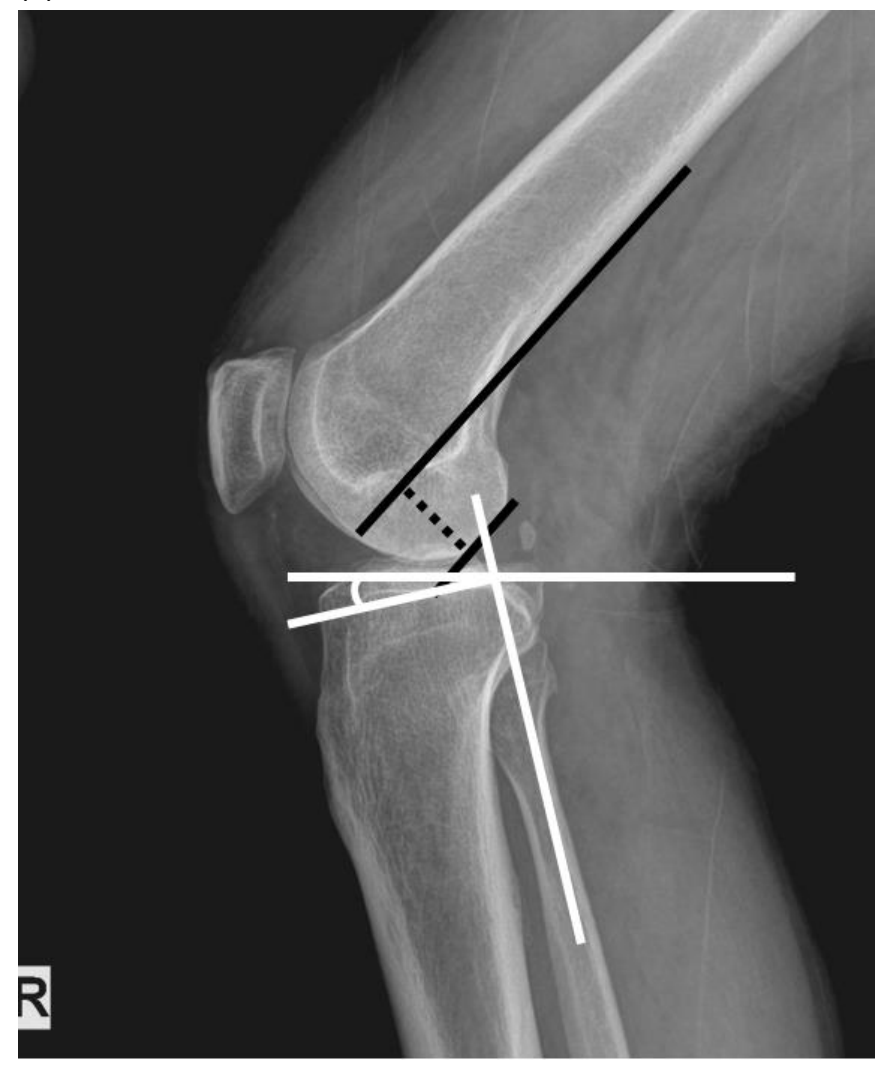

(b)

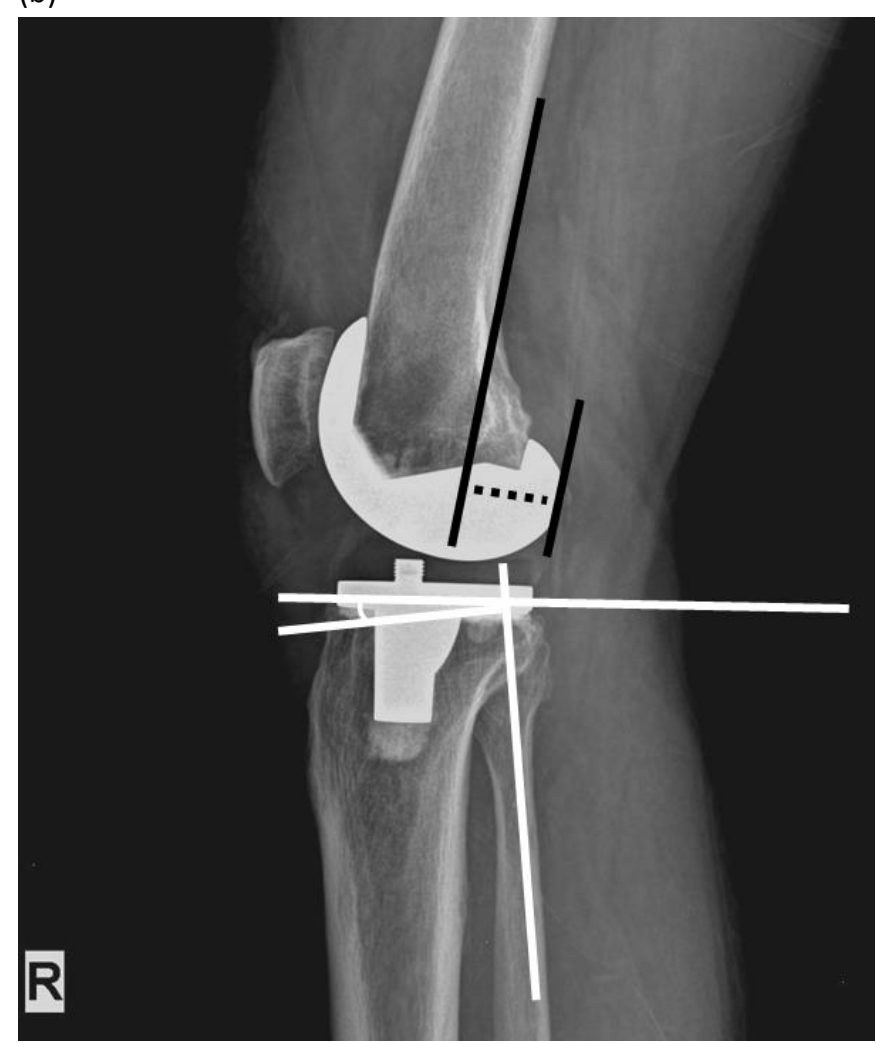


Figure 3: The correlation between posterior tibial slope and postoperative maximal flexion angle (Spearman rank

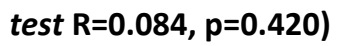

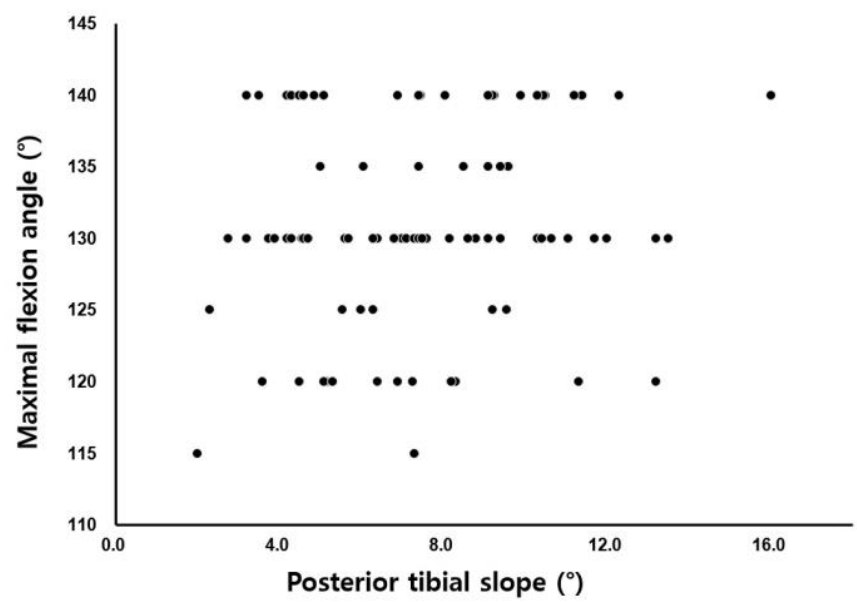

Figure 4: The correlation between femoral condylar offset and postoperative maximal flexion angle (Spearman rank test $\mathrm{R}=\mathbf{0 . 0 1 4}, \mathrm{p}=\mathbf{0 . 8 9 2}$ )

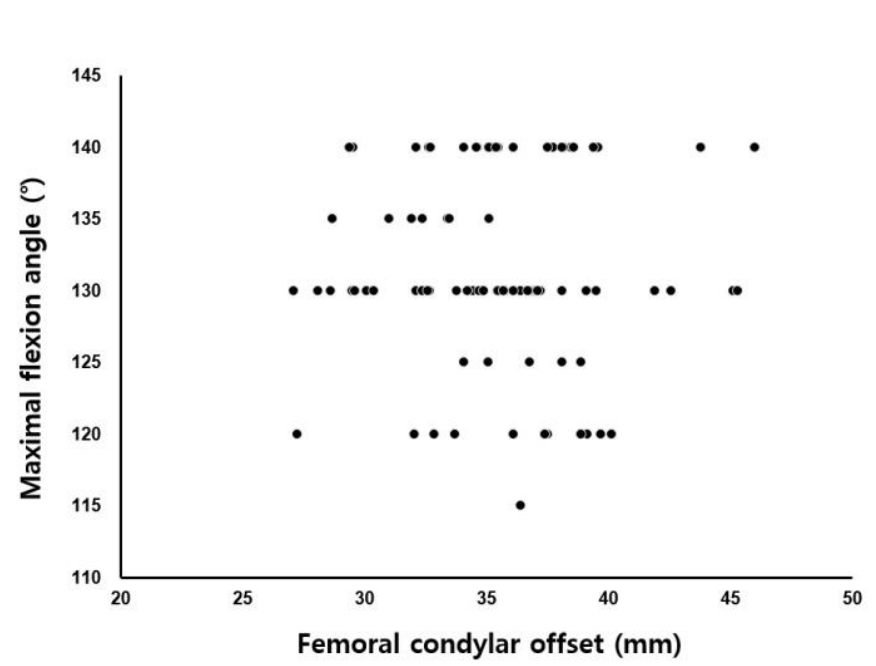

Table 1: Clinical outcome at preoperative and postoperative final follow-up

\begin{tabular}{|l|l|l|l|}
\hline & $\begin{array}{l}\text { Preoperative } \\
\text { Mean } \pm \text { SD }\end{array}$ & $\begin{array}{l}\text { Postoperative } \\
\text { Mean } \pm S D\end{array}$ & p-value \\
\hline${\text { ROM }\left({ }^{\circ}\right)}^{\text {Maximal }}$ & $120.4 \pm 13.5$ & $132.1 \pm 7.3$ & $\mathrm{p}<0.05$ \\
\hline $\begin{array}{l}\text { Flexion }\left(^{\circ}\right) \\
\text { Knee Score }\end{array}$ & $125.3 \pm 9.3$ & $134.7 \pm 7.5$ & $\mathrm{p}<0.05$ \\
\hline $\begin{array}{l}\text { Function } \\
\text { Score }\end{array}$ & $46.5 \pm 7.6$ & $77.3 \pm 5.7$ & $\mathrm{p}<0.05$ \\
\hline $\begin{array}{l}\text { SD Standard } \\
\text { Deviation }\end{array}$ & & $89.3 \pm 5.2$ & $\mathrm{p}<0.05$ \\
\hline
\end{tabular}

